\title{
Hemobilia after pseudoaneurysm of a right hepatic artery branch
}

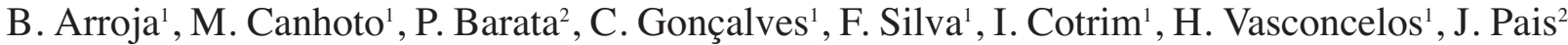 \\ and V. Pardal ${ }^{3}$
}

Departments of ${ }^{1}$ Digestive Diseases, ${ }^{2}$ Surgery, and ${ }^{3}$ Radiology. Hospital de Santo André. EPE. Leiria, Portugal

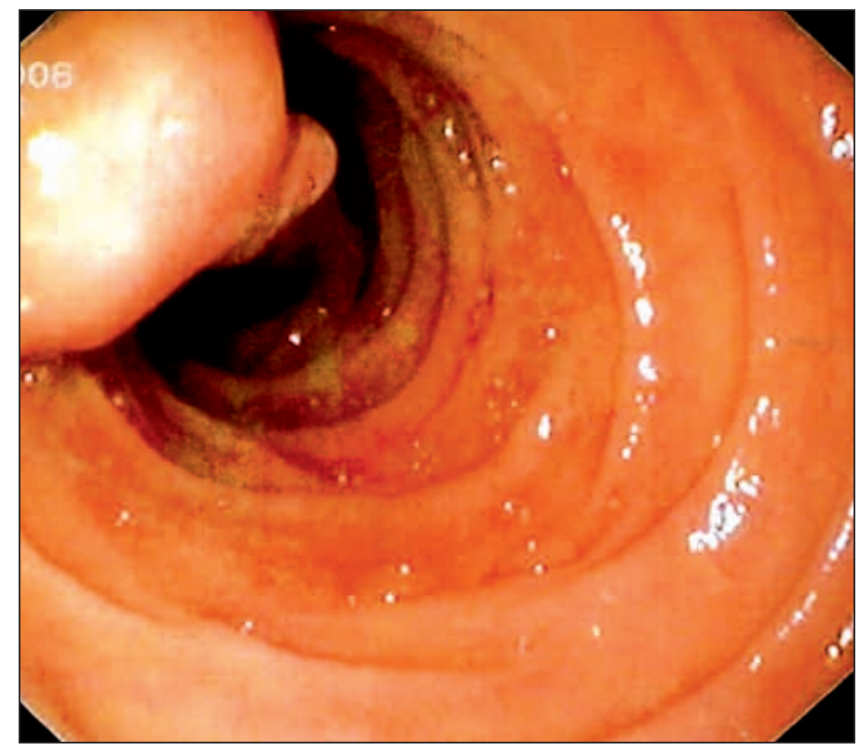

\section{CASE REPORT}

A 72 year-old male with previous history of coronary heart disease, diabetes and gallbladder lithiasis, regularly medicated with low dose aspirin and oral anti-diabetics drugs, was admitted at the emergency room complaining of severe right upper abdominal quadrant pain and hematemesis. Physical examination: pallor, BP 110/70 mmHg, HR 90 bpm; tender and distended abdomen and normal cardiac-pulmonary auscultation; normal rectal examination. Laboratory data: haemoglobin $7.5 \mathrm{~g} / \mathrm{dL}$, platelet count $230.000 / \mu \mathrm{L}$, INR 1.05 , blood-urea nitrogen $12.3 \mathrm{mg} / \mathrm{dL}$, ALT $130 \mathrm{U} / \mathrm{L}$, AST $130 \mathrm{U} / \mathrm{L}$, ALP $424 \mathrm{U} / \mathrm{L}$.

Fig. 1. Blood coming out from the papilla of Vater.

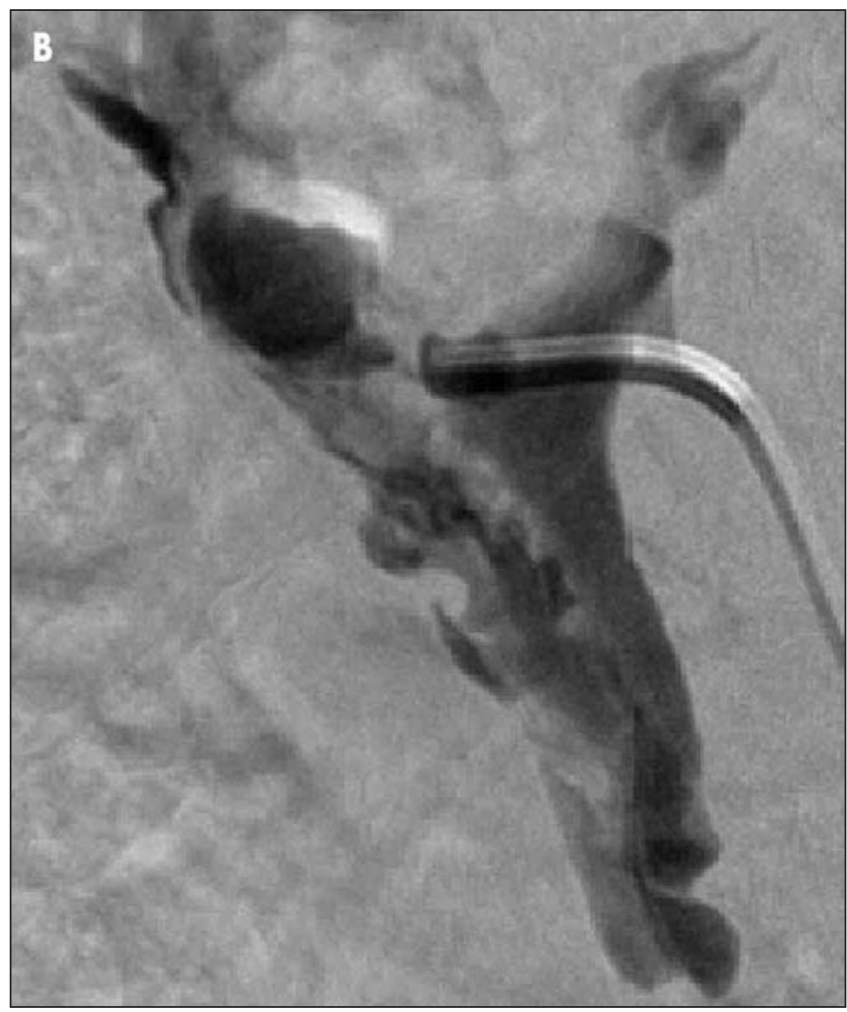

Fig. 2. A. Angiography -accumulation of contrast over the anatomic normal limit of a branch (red arrow) of the right hepatic artery (white arrow). B. After selective catheterization of the right hepatic artery, contrast was injected with opacification of the common bile duct (CBD) indicating fistula between artery and CBD. 


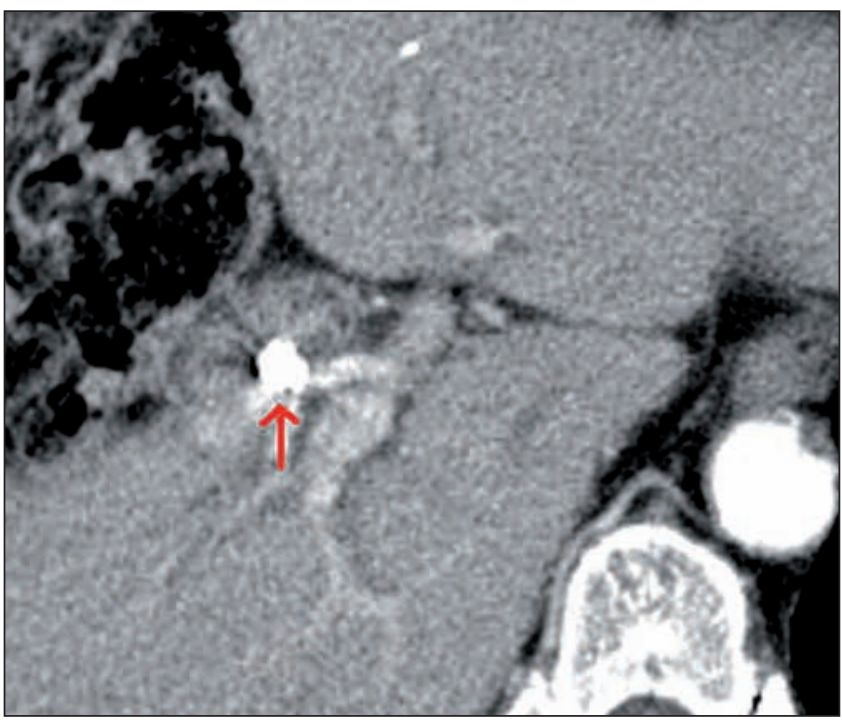

Fig. 3. CT scan shows hyperdense material (red arrow) from previous transcatheter embolization.

Esophagogastroduodenoscopy detected blood actively oozing from the papilla of Vater (Fig. 1). Computed tomography scan raised suspicion of an inflammatory aneurysm secondary to acute cholecystitis. Angiography suggested a pseudoaneurysm of a right hepatic artery branch (Fig. 2). Transcatheter embolization was done successfully and a follow-up CT scan performed one month later confirmed hyperdense embolization material in place (Fig. 3).

The patient refused subsequent cholecystectomy.

Two years later the patient presented with acute lithiasic cholangitis. Endoscopic retrograde cholangiopancreatography was unable to retrieve biliary stones despite multiple attempts. The patient eventually underwent cholecystectomy and biliary drainage rapidly improving his clinical situation.

\section{DISCUSSION}

Hemobilia is a rare hemorrhagic event that must be taken in consideration when upper gastrointestinal bleeding is suspected (1). Abdominal pain, hematemesis, melena and jaundice are typical features (2).

The major underlying precipitating conditions are hepatobiliary trauma, infectious diseases (colecystitis, liver abscess), neoplasms or vascular diseases (3-4).

Several published reports have provided evidence that interventional radiological techniques are of utmost value in diagnosing and treating cases of hemobilia, namely when pseudoaneurysms of hepatic or cystic arteries are responsible for the hemorrhagic event $(4,5)$.

\section{REFERENCES}

1. Akatsu T, Hayashi S, Egawa T, Doi M, Nagashima A, Kitano M, et al. Hepatic artery pseudoaneurysm associated with cholecystitis that ruptured into the gallbladder. J Gastroenterol 2004; 39(9): 900-3.

2. Maeda A, Kunou T, Saeki S, Aono K, Murata T, Niinomi N, et al Pseudoaneurysm of the cystic artery with hemobilia treated by arterial embolization and elective cholecystectomy. J Hepatobiliary Pancreat Surg 2002; 9(6): 755-8.

3. Welsch T, Hallscheidt P, Schmidt J, Steinhardt HJ, Büchler MW, Sido B. Management of a rare case of fulminant hemobilia due to arteriobiliary fistula following total pancreatectomy. J Gastroenterol 2006; 41(11): 1116-9.

4. Hidalgo F, Narváez JA, Reñé M, Domínguez J, Sancho C, Montanyà $X$. Treatment of hemobilia with selective hepatic artery embolization. J Vasc Interv Radiol 1995; 6(5): 793-8.

5. Defrayne L, Vanlangenhove P, De Vos M, Pattyn P, Van Maele G, Decruyenaere J, et al. Embolization as a first approach with endoscopically unmanageable acute nonvariceal gastrointestinal hemorrhage. Radiology 2001; 218(3): 739-48. 